\title{
Correction to: Simulation of the Precipitation Kinetics of Maraging Stainless Steels 17-4 and 13-8+Mo During Multi-pass Welding
}

\author{
ROBERT J. HAMLIN, JOHN N. DUPONT, and CHARLES V. ROBINO
}

https://doi.org/10.1007/s11661-019-05249-2

(C) The Minerals, Metals \& Materials Society and ASM International 2019

Correction to: Metallurgical and Materials Transactions A,

Volume 50A, February 2019, pp. 719-732

https://doi.org/10.1007/s11661-018-5046-9

IN the original article there are errors in Eqs. [6] and [7]. Following are the corrected Eqs.:

$$
\begin{gathered}
k=k_{1} \exp \left(\frac{-n^{\prime} Q_{\mathrm{o}}}{R T}\right) \\
x=1-\exp \left(\left(-k_{1} \exp \left(\frac{-n^{\prime} Q_{\mathrm{o}}}{R T}\right)\right)\left(t^{n^{\prime}}\right)\right)
\end{gathered}
$$

Publisher's Note Springer Nature remains neutral with regard to jurisdictional claims in published maps and institutional affiliations.

ROBERT J. HAMLIN and JOHN N. DUPONT are with Lehigh University, Bethlehem, PA, 18015. Contact e-mail: Rjh212@alum.lehigh.edu CHARLES V. ROBINO is with Sandia National Laboratories, Albuquerque, NM, 87185.

The original article can be found online at https://doi.org/10.1007/ s11661-018-5046-9.

Article published online April 25, 2019 